\title{
Intrarectal pressures and balloon expulsion related to evacuation proctography
}

\author{
S Halligan, J Thomas, C Bartram
}

\begin{abstract}
Seventy four patients with constipation were examined by standard evacuation proctography and then attempted to expel a small, non-deformable rectal balloon, connected to a pressure transducer to measure intrarectal pressure. Simultaneous imaging related the intrarectal position of the balloon to rectal deformity. Inability to expel the balloon was associated proctographically with prolonged evacuation, incomplete evacuation, reduced anal canal diameter, and acute anorectal angulation during evacuation. The presence and size of rectocoele or intussusception was unrelated to voiding of paste or balloon. An independent linear combination of pelvic floor descent and evacuation time on proctography correctly predicted maximum intrarectal pressure in $74 \%$ of cases. No patient with both prolonged evacuation and reduced pelvic floor descent on proctography could void the balloon, as maximum intrarectal pressure was reduced in this group. A prolonged evacuation time on proctography, in combination with reduced pelvic floor descent, suggests defecatory disorder may be caused by inability to raise intrarectal pressure. A diagnosis of anismus should not be made on proctography solely on the basis of incomplete/prolonged evacuation, as this may simply reflect inadequate straining. (Gut 1995; 37: 100-104)
\end{abstract}

Keywords: evacuation proctography, intrarectal pressure.

Evacuation proctography (EP) is commonly performed to investigate outlet obstruction in constipated patients. Proctography images structural rectal changes during voiding of a barium paste, ${ }^{1}$ also providing an estimate of the rate and degree of rectal emptying. ${ }^{2}$ The standard paste used, however, does not simulate the inspissated faeces in constipated patients. Evacuation of paste may be complete if excessive straining is performed to raise intrarectal pressure. Also, the maximum intrarectal pressure may serve to quantify the work performed when evacuating. Rectal balloon expulsion may be used as an alternative to EP, as inability to expel an intrarectal balloon can point to a disorder of rectal evacuation. ${ }^{3}$ This simple method has been adopted by many anorectal physiology units as a test for anismus. ${ }^{4}$ The balloons used tend to be comparatively large, however, and easily deformable, therefore attracting the same criticisms as barium paste.

Constipated patients tend to pass small, hard stools and therefore expulsion of a small, non-deformable balloon may be more relevant than paste or large balloons. Also, constipated patients may show rectal deformity such as rectocoele and intussusception on EP. Although there is evidence that these features do not impede evacuation of paste, ${ }^{5}$ their relation to expulsion of a solid bolus is unknown.

We have therefore compared the expulsion of a small, non-deformable balloon, using simultaneous imaging and intrarectal pressure monitoring with the findings on EP, to determine any relation between these parameters.

\section{Methods}

Subjects

Seventy four consecutive outpatients (nine male, 65 female), complaining of difficult or infrequent evacuation, or both and referred for evacuation proctography, were examined. Permission for the study was granted by the local ethics committee and all patients gave written, informed consent.

\section{Study design}

Before the procedure two glycerine suppositories were given rectally and patients asked to empty the rectum. Evacuation proctography was performed with a standard technique. With the patient in the left lateral position the rectum was filled with $120 \mathrm{cc}$ of barium paste (E-Z-paste, E-Z-Em, Westbury, NY), instilled by a bladder syringe and cut off Foley catheter. The patient was then seated upright on a specially designed commode and asked to empty the rectum as rapidly and completely as possible during lateral videofluoroscopy.

The patient was then returned to the left lateral position. A $16 \mathrm{~F}$ Foley catheter, prefilled with water and air free, was inserted into the proximal rectum and the balloon inflated to a diameter of $2.5 \mathrm{~cm}$ with $10 \mathrm{ml}$ of water soluble contrast. The catheter was connected to a physiological pressure transducer and chart recorder (SensoNor 840, Lectromed MX2P and MX216, Letchworth, UK), by a three way tap. The patient was then returned to the sitting position on the commode and asked to try and expel the rectal balloon, using intermittent videofluoroscopy to locate the position of the balloon in the rectum. Intrarectal pressure was displayed simultaneously on the 
TABLE I Ability to expel rectal balloon compared with EP parameters

\begin{tabular}{|c|c|c|c|}
\hline Evacuation proctography & $\begin{array}{l}\text { Balloon expelled } \\
(n=35) \\
\text { (median (range)) }\end{array}$ & $\begin{array}{l}\text { Balloon not } \\
\text { expelled }(n=39) \\
\text { (median (range)) }\end{array}$ & $\begin{array}{l}\text { Significance } \\
\text { (p Value) }\end{array}$ \\
\hline $\begin{array}{l}\text { Evacuation time }(\mathrm{sec}) \\
\text { Percentage evacuated } \\
\text { ARA at rest (degrees) } \\
\text { ARA on straining } \\
\text { Change in ARA on straining } \\
\text { Maximum AC width }(\mathrm{cm}) \\
\text { Pelvic floor descent }(\mathrm{cm}) \\
\text { Rectocele area (square } \mathrm{cm} \text { ) }\end{array}$ & $\begin{array}{l}10(3-50) \\
91(45-100) \\
120(76-150) \\
138(99-186) \\
15(-15 \text { to }+53) \\
1.8(0 \cdot 5-3 \cdot 9) \\
-3 \cdot 6(-8 \cdot 4 \text { to }-0 \cdot 5) \\
4 \cdot 3(1 \cdot 4-17 \cdot 4)\end{array}$ & $\begin{array}{l}30(5->60) \\
68(0-100) \\
116(73-166) \\
133(84-160) \\
11(-62 \text { to }+51) \\
1 \cdot 1(0-2 \cdot 0) \\
-3 \cdot 9(-7 \cdot 1 \text { to }-0 \cdot 5) \\
5 \cdot 4(1 \cdot 5-17 \cdot 0)\end{array}$ & $\begin{array}{l}<0.001 \\
<0.001 \\
\text { NS } \\
0.043 \\
\text { NS } \\
<0.001 \\
\text { NS } \\
\text { NS }\end{array}$ \\
\hline
\end{tabular}

${ }^{\star}$ Mann-Whitney $\mathrm{U}$ test. ARA $=$ anorectal angle, $\mathrm{AC}=$ anal canal.

videoproctogram recording, but to facilitate measurements intrarectal pressure was also recorded on a chart.

The videoproctogram of each examination was analysed using a computer video capture and digitising system, in conjunction with an image analysis program (DataTranslation, Wokingham, UK). The rate and completeness of rectal emptying was recorded; automated edge detection and image enhancement permitted precise identification of contrast/soft tissue boundaries allowing measurement of lateral rectal area before and after evacuation to estimate the percentage of contrast evacuated. ${ }^{2}$ Evacuation, timed from the initial opening of the anal canal to completion of rectal emptying, was measured in seconds from the video counter. The position of the pelvic floor at rest and on evacuation was measured and related to a fixed point (the upper surface of the commode). The anorectal angle (along the posterior rectal wall) at rest and on evacuation was measured. Maximum anal canal width on evacuation was noted. Rectal configuration at the end of evacuation was observed, and any infolding of the rectal wall to form an intussusception was noted. Intrarectal intussusception was defined as internal prolapse that remained confined to the rectum while any prolapse into the anal canal was described as intra-anal. ${ }^{6} \mathrm{~A}$ rectocoele was defined as any anterior bulge outside the line of the anterior rectal wall, occurring during straining. ${ }^{6}$ Rectocoele size was defined as the area anterior to a line drawn parallel to the anterior demarcation of the anal canal $^{7}$ and was measured planimetrically by video capture. This measurement was performed on the video frame showing the largest anterior rectal extension.

The ability to evacuate the rectal balloon was noted. The position of the rectal balloon was related to the upper surface of the commode and measured by video capture. Maximum intrarectal pressure and intrarectal pressure at maximum pelvic floor descent were recorded. The equipment was calibrated at regular intervals and the video analysis program adjusted to compensate for radiographic magnification.

\section{Statistical analysis}

Statistical analysis was performed with Minitab Version 8.2 (Minitab, State College, PA) and SPSS Version 4.01 (SPSS, Watford, UK). Descriptive statistics and univariate tests of significance provided basic information about differences among groups. The MannWhitney $U$ test statistic was used to analyse unpaired, non-parametric, continuous data. Fisher's exact test was used to examine data that could be expressed in a $2 \times 2$ contingency table. Discriminant analysis was used in 57 patients in whom there were no missing variables, to discover if any of the measured variables distinguished between the groups, and thus influenced rectal evacuation. Statistical significance was assigned to any probability value of less than 0.05 .

\section{Results}

Ability to evacuate the balloon

Thirty nine of 74 patients examined could not expel the rectal balloon (53\%). Inability to expel the balloon was significantly associated with EP parameters of prolonged and incomplete evacuation, a narrow anal canal width, and a more acute anorectal angle during evacuation (Table I).

Twenty patients who could not evacuate the balloon took longer than 30 seconds to evacuate on EP, in contrast with only three patients who could void the balloon $(p<0.001$, Fisher's exact test). Eighteen of the patients who could not evacuate the balloon evacuated less than two thirds of the rectal contrast compared with four who could void the balloon $(p=0.002$, Fisher's exact test).

\section{Intrarectal pressure}

Overall, there was no significant difference in maximum intrarectal pressure comparing those able to void the balloon with those who could not (median $208 \mathrm{~cm} \mathrm{H}_{2} \mathrm{O} v$ 143). The distribution of maximum intrarectal pressure data was divided into three groups (low $<100$ $\mathrm{cm} \mathrm{H}_{2} \mathrm{O}$, mid 101-200 $\mathrm{cm} \mathrm{H}_{2} \mathrm{O}$, and high $>201 \mathrm{~cm} \mathrm{H}_{2} \mathrm{O}$ ) and discriminant analysis used to discover if any of the measured variables distinguished between the groups. Fifty seven patients were entered into the discriminant analysis. An independent linear combination of pelvic floor descent $(p<0.001)$ and evacuation time $(p<0.001)$ correctly predicted the intrarectal pressure in $74 \%$ of cases overall (Table II). Eight patients had an evacuation time in excess of 30 seconds combined with pelvic floor descent of less than $3.0 \mathrm{~cm}$. Median maximum intrarectal pressure in this group was $52.5 \mathrm{~cm} \mathrm{H}_{2} \mathrm{O}$ and no patient could void the balloon.

TABLE II Does the evacuation time and pelvic floor descent predict intrarectal pressure (IRP)?

\begin{tabular}{llcll}
\hline \multirow{2}{*}{$\begin{array}{l}\text { Actual IRP } \\
\left(\mathrm{cm} \mathrm{H}_{2} \mathrm{O}\right)\end{array}$} & \multicolumn{4}{l}{ Predicted IRP $\left(\mathrm{cm} \mathrm{H} \mathrm{H}_{2} \mathrm{O}\right)$} \\
\cline { 2 - 5 } & $0-100$ & $101-200$ & $201+$ & Total \\
\hline $0-100$ & $12(71 \%)$ & 5 & 0 & 17 \\
$101-200$ & 2 & $17(85 \%)$ & 1 & 20 \\
$201+$ & 1 & 6 & $13(65 \%)$ & 20 \\
Total & 15 & 28 & 14 & 57 \\
\hline
\end{tabular}

Figures in parentheses $=\%$ agreement. 
TABLE III Effect of rectocoele

\begin{tabular}{llll}
\hline & $\begin{array}{l}\text { Rectocoele present } \\
(n=57) \\
(\text { median (range) })\end{array}$ & $\begin{array}{l}\text { Rectocoele absent } \\
(n=17) \\
(\text { median (range) })\end{array}$ & $\begin{array}{l}\text { Significance } \\
(p \text { Value) }\end{array}$ \\
\hline $\begin{array}{l}\text { Evacuation time (sec) } \\
\text { Percentage evacuated }\end{array}$ & $22(3-60)$ & $23(5-60)$ & NS $^{\star}$ \\
Able to evacuate balloon & $26(3-100)$ & $66(0-100)$ & NS $^{\star}$ \\
\hline
\end{tabular}

${ }^{\star}$ Mann-Whitney $U$ and + Fisher's exact test.

\section{Rectal structural abnormality}

Fifty seven patients had rectocoeles $(77 \%)$. The presence and size of rectocoele did not influence evacuation of either paste or balloon (Tables I and III). Also, ability to evacuate either paste or balloon was not impaired by the presence of rectal intussusception, which was seen in 24 patients $(32 \%)$ (Table IV).

\section{Discussion}

For normal rectal evacuation to occur there must be an adequate pressure gradient from rectum to anus. This is achieved as a result of complex contraction and relaxation of smooth and striated muscle. Intrarectal pressure is raised by both colonic/rectal propulsive contraction $^{8}$ and raised intrapelvic pressure, achieved by voluntary contraction of the diaphragm and abdominal muscles. Accompanying involuntary relaxation of the internal anal sphincter and striated muscle surrounding the anorectal junction and anus permits passage of the faecal bolus. Defecation can require little voluntary effort if the smooth muscle propulsive action is pronounced ${ }^{9}$ but may be achieved at will, purely by voluntary striated muscular activity. ${ }^{10}$ This is the case during EP, which tests voluntary rectal evacuation, and a 'zone of evacuation' seems localised to the rectal ampulla on the lateral view. ${ }^{11}$ Thus normal evacuation requires both adequate intrarectal pressure and a relaxed anal canal.

While normal subjects evacuate rapidly and completely, ${ }^{12}$ some constipated patients have difficulty evacuating either liquid or semisolid contrast agents. In a study of 58 patients with idiopathic constipation, a prolonged evacuation time and incomplete emptying compared with controls was found. ${ }^{13}$ Failure of evacuation may be caused by inappropriate contraction of striated pelvic floor and anal muscles during attempted voiding, and is termed anismus. ${ }^{14}$ Evacuation can occur despite sphincteric contraction, however, if intrarectal pressure is raised high enough. In a study of patients with solitary rectal ulcer syndrome and paradoxical sphincter contraction, the measured rise in intrarectal pressure during voiding was found to be significantly

TABLE IV Effect of rectal intussusception

\begin{tabular}{llll}
\hline & $\begin{array}{l}\text { Intussusception present } \\
(n=24) \\
(\text { median (range) })\end{array}$ & $\begin{array}{l}\text { Intussusception absent } \\
(n=50) \\
(\text { median (range) })\end{array}$ & $\begin{array}{c}\text { Significance } \\
(p \text { Value })\end{array}$ \\
\hline Evacuation time $(\mathrm{sec})$ & $10(5-30)$ & $28(3-60)$ & $<0.001^{\star}$ \\
Percentage evacuated & $93(24-100)$ & $70(0-100)$ & $<0.001^{\star}$ \\
Able to evacuate balloon & 17 & 18 & $0.007 \dagger$ \\
\hline
\end{tabular}

${ }^{\star}$ Mann-Whitney $U$ and $†$ Fisher's exact test. higher than controls. ${ }^{15}$ Comparatively little work has been carried out to investigate the intrarectal pressures generated during evacuation of rectal content. Our study has shown that intrarectal pressures in excess of $200 \mathrm{~cm}$ $\mathrm{H}_{2} \mathrm{O}$ can be generated by constipated patients when attempting to expel a small, nondeformable balloon. Both normal and constipated patients find it more difficult to expel stools that are small and hard rather than large and soft, as the work required (a product of intrarectal pressure and straining time) to expel an intrarectal sphere varies inversely with its diameter. ${ }^{16}$ Thus higher pressures may be necessary to expel small balloons in contrast with those that are large and deformable.

Inability to voluntarily raise intrarectal pressure may account for evacuation failure despite normal pelvic floor relaxation. We showed a complex interrelation between intrarectal pressure, pelvic floor descent, and evacuation time. Seventeen patients $(30 \%)$ entered into the discriminant analysis generated intrarectal pressures below $100 \mathrm{~cm} \mathrm{H}_{2} \mathrm{O}$ and in eight cases this was also associated with decreased pelvic floor descent, a prolonged evacuation time, and failure to evacuate the balloon. Pelvic floor descent may be opposed by increased tension in the pelvic floor musculature, as occurs in anismus. Our results suggest, however, that adequate voluntary effort during EP will overcome this tension and result in satisfactory pelvic floor descent in most cases. Thus, subnormal pelvic floor descent on EP, in the presence of prolonged evacuation, suggests failure to raise intra-abdominal pressure as a cause of inadequate evacuation. A previous study relating intrarectal pressure to evacuation of paste in constipated patients suggested that failure to make a genuine straining effort could lead to the overdiagnosis of anismus. ${ }^{5}$

Failure to adequately raise intrarectal pressure is probably unconscious. Embarrassment during the procedure is a possible explanation. Also inability to voluntarily coordinate pelvic muscle manoeuvres is recognised in patients who have suffered sexual abuse early in life ${ }^{17}$ and this phenomenon may stem from a subconscious desire to dissociate themselves from their own pelvis. It may be that anismus is merely part of a spectrum of generalised pelvic floor incoordination, where some patients have increased pelvic floor tension during evacuation and others are unable to raise intrarectal pressure.

Despite anorectal manometry and anal electromyography, the importance of EP for the diagnosis of anismus is increasingly recognised as no single method has been universally adopted. ${ }^{18}$ We found excellent agreement between inability to evacuate rectal paste and the balloon, suggesting the disorded defecation is independent of the nature of rectal content. Thus the standard, semisolid contrast used for EP would seem to be appropriate for the diagnosis of anismus. An acute anorectal angle and narrow anal canal during evacuation, seen in the group with delayed/incomplete rectal emptying, are features previously described in anismus. ${ }^{19}$

Constipated patients may show rectal 
deformity on EP such as rectocoele and intussusception $^{20}$ and proctography is recommended to diagnose internal rectal intussusception as a cause of obstructed defecation. ${ }^{4}$ However, the contribution of intussusception to outlet obstruction is unclear. It is unknown whether prolapse actually impedes rectal evacuation or is merely an association as similar findings may be shown independent of clinical symptoms and may not influence rectal emptying. ${ }^{21}$

The paste used for EP does not simulate inspissated stool. It is claimed that prolapsing folds may impede evacuation of solid faeces, where paste would be easily passed. We found, however, that the presence of intussusception did not impede evacuation of either paste or balloon. We placed the rectal balloon into the proximal rectum, so that initially it lay above any intussusception. Despite this, intussusception did not seem to impede passage of the balloon as intermittent fluoroscopy showed that any intussuscepting fold was displaced out of the way as the balloon was expelled. This finding is in accordance with other studies suggesting the intussusception does not impair rectal emptying. ${ }^{5}$ Also, elimination of intussusception in patients with obstructed defecation is not associated with clinical improvement, suggesting that the defecatory disorder is not primarily caused by prolapse. ${ }^{22}$

In our study, patients with intussusception were more likely to evacuate paste completely than those without. High grade intussusception is best seen on EP, however, when the rectum is nearly empty, suggesting that these patients can void adequately, although they may experience feelings of incomplete evacuation because of the prolapse. Intussusception is visualised less in patients with anismus, where emptying is incomplete. For example, the diagnosis of intra-anal intussusception is best made with an empty rectum. ${ }^{23}$

Rectocoeles are common in women and considered a normal variant, unrelated to constipation. ${ }^{24}$ However, a large rectocoele may be considered abnormal and repaired surgically. Although trapping of barium on EP is believed to point to a functionally significant rectocele, it is possible that paste may not sequester in a rectocoele as might solid stool. In our study, however, the presence or size of rectocoele was unrelated to ability to expel the balloon or paste, suggesting again that no additional benefit is gained from visualising balloon expulsion. The contribution of rectocoeles to defecatory disorder is complex and unclear. There is no doubt that some patients with a large rectocoele can only evacuate with the help of digital manoeuvres to support the rectovaginal septum and these patients may benefit from surgical repair. However, rectocoeles may be associated with anismus in up to $71 \%$ of cases. ${ }^{25}$ Where anismus and a large rectocoele are seen together, it may be unclear what is the primary cause of obstructed defecation.

In conclusion, we have investigated expulsion of a small rectal balloon to simulate a faecal bolus. Use of the balloon conveyed no advantage over standard barium paste as failure to expel the balloon was closely associated with prolonged and incomplete evacuation on EP. Thus defecatory disorder seems independent of the nature of rectal content. Also, imaging of balloon expulsion suggests that rectocoele and intussusception may not mechanically impede rectal evacuation. A complex relation exists between the intrarectal pressure, pelvic floor descent, and evacuation time. Prolonged evacuation time on EP, in combination with reduced pelvic floor descent, suggests defecatory disorder may be caused by inability to raise intrarectal pressure. Paradoxical sphincter contraction (anismus) should not be diagnosed from EP solely on the basis of prolonged and incomplete evacuation as this may simply reflect an inadequate straining effort.

Steve Halligan was supported by the St Mark's Research Foundation. The authors are grateful to Abbey Sullivan, Anna Giles, and Jocelyn Sewell for technical assistance.

Read at the spring meeting of the British Society of Gastroenterology, UMIST, Manchester, England, 23-25 March 1994 and at the annual meeting of the European Society of Gastrointestinal Radiologists, Taormina, Sicily, 1-4 June 1994.

1 Mahieu P, Pringot J, Bodart P. Defecography: 1. Description of a new procedure and results in normal patients. Gastrointest Radio 1984; 9: 247-51.

2 Halligan S, McGee S, Bartram C. Quantification of evacuation proctography. Dis Colon Rectum 1994; 37: 1151-4.

3 Barnes P, Lennard-Jones JE. Balloon expulsion from the rectum in constipation of different types. Gut 1985; 26: 1049-52.

4 Fleshman J, Dreznik Z, Cohen E, Fry R, Kodner I. Balloon expulsion test facilitates diagnosis of pelvic floor outlet obstruction due to nonrelaxing puborectalis muscle. obstruction due to nonrelaxing pube
Dis Colon Rectum 1992; 35: 1019-25.

5 Roberts J, Womack N, Hallan RI, Thorpe A, Williams NS. Evidence from dynamic integrated proctography to redifine anismus. Br F Surg 1992; 79: 1213-5.

6 Shorvon P, McHugh S, Diamant N, Somers S, Stevenson G. Defecography in normal volunteers: results and implications. Gut 1989; 30: 1737-49.

7 Ting K, Mangel E, Eibl-Eibesfeldt B, Muller-Lissner S. Is the volume retained after defecation a valuable parameter at defecography? Dis Colon Rectum 1992; 35: 762-7.

$8 \mathrm{Kamm} \mathrm{MA,} \mathrm{van} \mathrm{der} \mathrm{Sijp} \mathrm{J,} \mathrm{Lennard-Jones} \mathrm{JE.} \mathrm{Observations}$ on the characteristics of stimulated defecation in severe idiopathic constipation. Int $\mathcal{f}$ Colorect Dis 1992; 7: 197-201.

9 Heaton K, Ghosh S, Braddon F. How bad are the symptoms and bowel dysfunction of patients with the irritable bowel syndrome? A prospective controlled study with emphasis on stool form. Gut 1991; 32: 73-9.

10 Lennard-Jones JE. Clinical classification of constipation. In: Kamm M, Lennard-Jones JE, eds. Constipation. Petersfield: Wrightson Biomedical, 1994.

11 Bartram CI, Turnbull G, Lennard-Jones JE. Evacuation proctography: an investigation of rectal expulsion in 20 subjects without defecatory disturbance. Gastrointestinal Radiology 1988; 13: 72-80.

$12 \mathrm{Kamm}$ MA, Bartram CI, Lennard-Jones JE. Rectodynamics-Quantifying rectal evacuation. Int $\dot{f}$ Colorect Dis 1989; 4: 161-3.

13 Turnbull G, Bartram CI, Lennard-Jones JE. Radiological studies of rectal evacuation in adults with idiopathic constipation. Dis Colon Rectum 1988; 31: 190-7.

14 Preston D, Lennard-Jones JE. Anismus in chronic constipation. Dig Dis Sci 1985; 30: 413-8.

15 Womack N, Williams NS, Holmfield J, Morrison J. Pressure and prolapse - the cause of solitary rectal ulceration. Gut 1987; 28: 1228-33.

16 Bannister J, Davison P, Timms J, Gibbons C, Read NW. Effect of stool size and consistency on defecation. Gut 1987; 28: 1246-50.

17 Drossman D, Lesserman J, Nachman G, Garrick H, Toomey TC, Mitchell CM. Sexual and physical abuse in women with functional or organic gastrointestinal disorders. Ann Intern Med 1990; 113: 828-33.

18 Ger G, Wexner S, Jorge J, Salanga V. Anorectal manometry in the diagnosis of paradoxical puborectalis syndrome. in the diagnosis of paradoxical pub

19 Jorge J, Wexner S, Ger G, Salanga V, Nogueras J, Jagelman $D$. Cinedefecography and electromyography in the diagnosis of nonrelaxing puborectalis syndrome. Dis Colon Rectum 1993; 36: 668-76.

20 Berman I, Manning H, Dudley-Wright K. Anatomic specificity in the diagnosis and treatment of internal rectal prolapse. Dis Colon Rectum 1985; 28: 816-26.

21 Nielsen M, Buron B, Christiansen J, Hegedus V. 
Defecographic findings in patients with anal incontinence and constipation and their relation to rectal emptying. Dis Colon Rectum 1993; 36: 806-9.

22 Orrom W, Bartolo D, Miller R, Mortensen N, Roe A. Rectopexy is an ineffective treatment for obstructed defecation. Dis Colon Rectum 1991; 34: 41-6.

$23 \mathrm{McGee}$ S, Bartram CI. Intra-anal intussusception: diagnosis by posteroanterior stress proctography.
Abdom Imaging 1993; 2: 136-40.

24 Yoshioka K, Matsui Y, Yamada O, Sakaguchi M, Takada $H$, Hioki K, et al. Physiological and anatomic assessment of patients with rectocele. Dis Colon Rectum 1991; 34: 704-8. 25 Johansson C, Nilsson BY, Holmstrom B, Dolk A, Mellgren A. Association between rectocele and paradoxical sphincter response. Dis Colon Rectum 1992; 35: 503-9. 